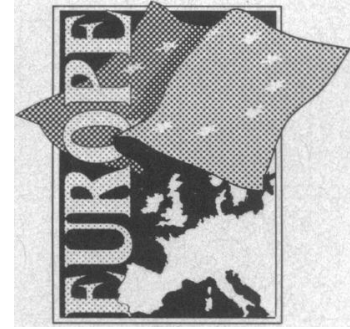

This is the twelfth of a series of articles looking at medical issues in Europe.

\section{Nursing in Europe}

Kirsten Stallknecht

When discussion began among European professional groups about harmonising educational standards the anxiety was that member states would be asked to change their individual systems to a standardised European version. Attitudes changed, however, as a result of the Dahrendorf hearing in 1973, when the ministers of education decided that instead of a general harmonising of education the new approach should be the establishment of a set of minimum standards. This would simplify and speed up the process of allowing the free movement of people and services within the European community (EC).

This new approach forced the professional associations representing nurses and other health professionals to reassess their attitudes, but these organisations were still mostly concerned with protecting their own interests rather than with the advancement of the unity of the EC. Mostly, too, they continued to believe that the system in their own country was the best.

The EC agreed directives for many professions in the 1970s, and doctors and nurses were among these. Nevertheless it was the political decision to form a single market that gave real, practical importance to the concept of free movement. We now need to recognise that the Europe of the 1990s is changing dramatically - and that developments in the Eastern bloc states will force even further changes. In the long run the living and working conditions, the health and education services, and so on cannot be allowed to differ as widely as at present between eastern and western Europe.

\section{Nurses' cooperation}

In the late 1960s the nurses of Europe began to meet and eventually formed a group of nurses' associations in the EC member countries and countries applying for membership. The Standing Committee of Nurses of the EC (PCN) was formally established in 1971. Its main task was to promote better educational standards for nurses in the EC and-especially after the Dahrendorf hearing - to help develop directives on general nursing education and the free movement of nurses in Europe. Considerable differences were soon apparent in the educational systems, and the first task of the PCN was to agree a set of common minimum requirements to be implemented through the directives. These requirements were met in 1977 with two directives, 452 and 453 , on "the mutual recognition of diplomas, certificates and other evidence of the formal qualifications of nurses responsible for general care" and "the coordination of provisions laid down by law, regulation, or administrative action in respect of the activities of nurses responsible for general care."

In some countries this agreement on minimum standards led to improvements in the standard of education for nurses; in others it left education unchanged. The main fear among the leaders of European nurses had been that the minimum standards would prevent the more advanced countries from developing better educational programmes. In practice this has not proved to be so. In most of the countries of the EC educational programmes have continued to evolve and improve.

\section{Nursing numbers}

No reliable statistics on nurses and nursing personnel are available for the EC, but some figures can be extracted from the Vienna conference material. The general trend in Europe is for continuing growth in the demand for nurses, but demographic changes will make satisfaction of this demand difficult. The European office of WHO has estimated that 21 European countries will have less than $30 \%$ of their population under 20 years by the year 2000 . Only six countries are expected to see a rise in the numbers of young people. At the same time the numbers of old people will continue to grow.

\section{General development}

Once the PCN had been formed it seemed natural for nurses to extend their cooperation to other areas. One problem with this project was that general statistics on nursing and nurses proved not to be available. Indeed they are still not available in a form suitable for the PCN to embark on planning for the future. Nevertheless, some progress has been made. One valuable initiative has been the work done by the European office of the World Health Organisation on nursing as part of the health field. The WHO's medium term programme in nursing and midwifery has inspired the leaders of European nurses, and the "Health for All" programme has encouraged nurses to take a much more active role in health planning and promotion. This was very apparent at the WHO European nursing conference in Vienna in 1988, when a joint declaration on nursing and nursing education in Europe was adopted unanimously by the representatives from all European countries. ${ }^{1}$ The role of the nurse was defined at the meeting as one based on a generalist training with strong links with primary health care and with the possibility of further education in various clinical speciality fields, in management, education, and research.

The minimum requirement for nursing education in the EC was agreed as a three year course combining theoretical and practical work, and based on 12 years of basic and high school education. An annex has recently been added to the directives to secure implementation of the primary health care element in each EC country's programme.

Demographic changes, demands for more qualified professional workers at lower costs, changes in primary health care, and advances in medical treatment and technology will all increase the needs for both generalist registered nurses and those with specialist skills. Until now specialist education for nurses has varied widely in different European countries.

In some countries nurses have been educated in specific specialist areas such as psychiatry without having first had a general training. Specialist nurses of this kind are not allowed to work freely as nurses within the EC; the directive on free movement clearly states that it applies only to registered nurses with a generalist education.

In other countries nurses include one or two 
specialities within their general education, and in still other countries specialty education is always a form of further education after the general course has been completed. To preserve flexibility the European nurses' leaders decided that to comply with the directives specialty education should come after a general education. They also agreed that specialties should be widely interpreted in this context and should not be confined to the traditional fields. Further education programmes are now being developed to cover a wide range of topics.

Nursing research, too, is changing rapidly from small closed enclaves to a much more open setting. A group of European nurse researchers has been formed and a secretariat established. All over Europe nurses are working on the development of nursing performance standards and the registration of nursing data. This trend is further advanced in North America, but the systems developed there are closely related to the private health care system-and that is not what European nurses want.

One question still being discussed is whether the clinical responsibilities for nurses are comparable in the EC countries. The traditional role of nurses is different from one country to another, as is their position in the health hierarchy.

Coming changes in Europe, including the movement of people, businesses, and services, will stress the health sectors in every country; but at the same time there will be political pressure in every country for health care delivery to match the highest standards. Nurses expect these trends to lead to the roles of nurses in European countries becoming more closely comparable.

\section{Nurses's social challenges}

Minimum employment standards for nurses as laid down in the International Labour Office document 149 have not yet been secured in all countries. The convention was agreed in 1977, and since then 30 countries in the EC area have adopted it. Even though the WHO may provide technical assistance, including comparative statistics, for workforce planning in individual countries, reliable data are not yet available for Europe. At the moment the ILO is conducting a survey of nursing staff, but whether valid figures will emerge remains to be seen. The Nursing Times has collected some data on salaries (figure).

The poor pay and working conditions for nurses in many countries have led to increasing unrest, with strikes in Britain and France. The tradition has been that nurses' salaries and the compensatory payments for night and Sunday duties have been lower than for other comparable groups such as teachers, police

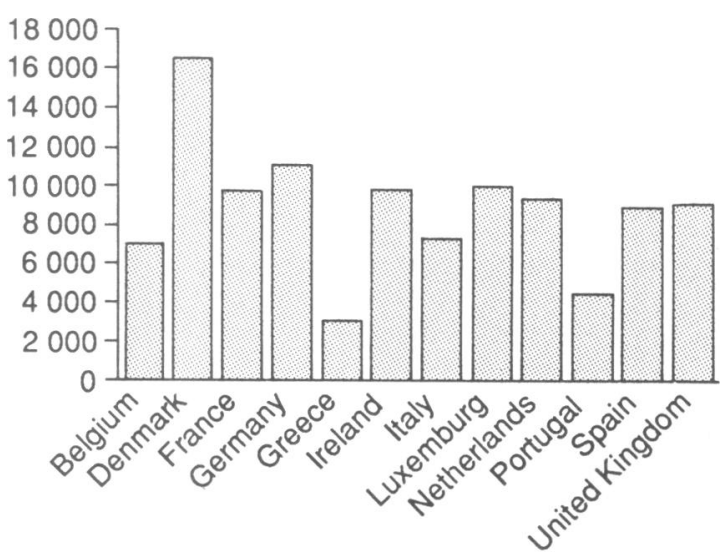

Annual salary (£) for newly qualified nurses

officers, and bank staff. This is partly a consequence of factors such as the close links between nursing and religious orders and partly because nursing is still mainly a profession for women. Nevertheless, in Europe attitudes to working women are changing rapidly and demands must be expected to grow for improvements in nurses' conditions.

The same trends are to be expected in the career structure. In many European countries the education of nurses has traditionally been a responsibility of the medical profession. This has already changed in some EC countries, in which nursing schools have nurse leadership. Animated discussions are continuing about whether nurses and nursing have their own identity and may make their own decisions in hospitals and in the primary health sector. Nurses claim this as a right in all sectors.

\section{The new challenges}

The next 10 years will present many new challenges for the professions in Europe, and especially for the health professions. We do not expect the EC to issue directives on how to run hospitals or other health institutions, but we do expect minimum requirements to be set on health promotion activities and on health hazards. The full implementation of the social charter (in countries other than Britain) will also influence the health sector. Examples include the directives on the protection of pregnant women and women with small children and on workers with night shifts and changing duties.

The full implementation of coming directives on environmental matters will require nurses and doctors to take part in the discussions, since these questions are of great importance for health promotion and medical treatment.

As more citizens move from one country to another the whole health sector will need to become more flexible in its services and its educational systems. Many of the differences we know and live with today in the health sector will not be tolerated by the EC in the long run. Clearly, economic restraints will not allow limitless resources for health, but demands will continue to increase and this could lead to downward pricing of professional services. Doctors and nurses can fight this development, or we can choose to become the standard setters as advisers to the politicians. I prefer the second option.

\footnotetext{
1 World Health Organisation. Summury report. European conference on nursing, V'ienna, 2l-24 June 1988. Copenhagen: WHO Regional Office for Europe, Tienna, $21-24$ June 1988 . Cop
} 2 Sevmour J. European round-up. Nursing Times 1990;86(48):38-41. 